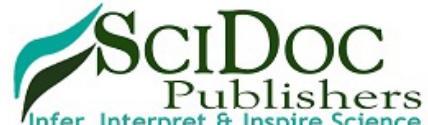

\author{
International Journal of Dentistry and Oral Science (IJDOS) \\ ISSN: 2377-8075
}

\title{
Cytokeratin overexpression in Submandibular Salivary Glands of Rats Treated with Botulinum Toxin and Epidermal Growth Factor
}

\author{
Research Article
}

Mahmoud M Bakr ${ }^{1}$, Mahmoud M Al Ankily¹, Mohamed Shamel²

${ }^{1}$ Director of Clinical Education, School of Medicine and Dentistry, Griffith University, Queensland, Australia.

${ }^{2}$ Lecturer, Oral Biology Department, Faculty of Dentistry, The British University in Egypt, Cairo, Egypt.

\section{Abstract}

Botulinum toxin (BTX) is used in different cosmetic and therapeutic procedures. In dentistry, BTX has been used successfully for management of drooling. BTX injection into salivary glands has damaging adverse effects on all components of the gland. Epidermal Growth Factor (EGF) is well known for its regenerative properties. The aim of this study was to investigate the effect of BTX injections on the submandibular salivary glands of adult female Albino rats, when administered solely or in conjunction with EGF through measuring the expression of cytokeratin in the parenchyma of the gland. Sixty rats were used in this study and were equally divided into control (saline) group, BTX group and EGF + BTX group (Combined treatment). The results obtained from this study showed that cytokeratin expression in submandibular salivary glands of rats significantly decreased after a single subcutaneous injection of 2.5 units of BTX in $0.1 \mathrm{ml}$ saline. However, daily intraperitoneal injections of EGF with a dose of $10 \mu \mathrm{g} / \mathrm{Kg}$ body weight restored normal levels of cytokeratin expression, as well as normal integrity of the submandibular salivary glands. Further studies are necessary to confirm the finding from the current study through immunohistochemical localization of E-cadherin as well as scanning electron microscopy examination of submandibular salivary glands treated with BTX and EGF.

Keywords: Submandibular Salivary Gland; Epidermal Growth Factor; Botulinum Toxin; Clostridium; Cytokeratin.

\section{Introduction}

Botulinum toxin (BTX) is produced by a Gram-positive rodshaped anaerobic bacterium, Clostridium botulinum and few similar Clostridia (C. butyricum, C. baratii and C. argentinense) [1]. BTX is a protein complex consisting of a neurotoxic part that targets synaptic proteins involved in vesicular neurotransmitter release. There are seven well known antigenically distinct BTX serotypes (A-G), with the most recent serotype $\mathrm{H}$ being reported and currently characterized [2, 3]. Additionally, these serotypes also have further subtypes $[4,5]$.

The cosmetic use of BTX was first reported in 1992 as a safe and simple procedure that is more effective than soft tissue augmentation and then in 2000 the FDA approved botulinum type A (BTXA) and botulinum type B (BTXB) as treatments for cervical dystonia and glabellar (frown) lines [6]. Since the introduction of
BTX into the health field, it has become a versatile drug in various fields of medicine. The clinical applications of BTX continue to expand and additional novel applications are becoming popular [7].

The pharmacological inhibition of salivary glands by intra-glandular injection of BTX leads to blocking of acetylcholine release at the neuro-glandular junction and produces a distinct reduction in salivary flow [8]. All neurotoxin types suppress secretion of acetylcholine at nerve endings. However, type $\mathrm{A}$ is the most researched, and studies about the effects of other serotypes are well on track [9].

BTX injection into the salivary glands is a safe and effective method of drooling treatment. Success rates as high as $89 \%$ to $95 \%$ were evident when injected in major salivary glands. As BTX is injected locally, this averts the systemic side effects seen with anticholinergic medications [10].

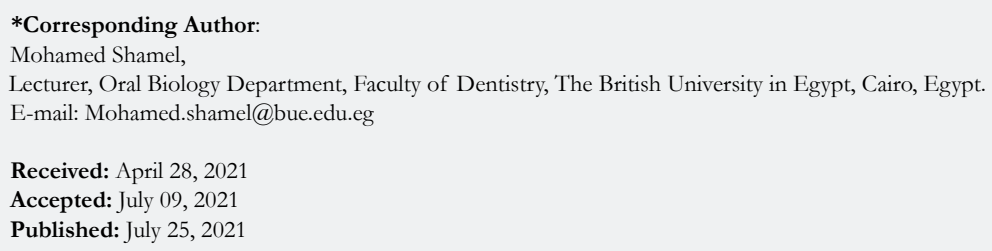

Citation: Mahmoud M Bakr, Mahmoud M Al Ankily, Mohamed Shamel. Cytokeratin overexpression in Submandibular Salivary Glands of Rats Treated with Botulinum Toxin and Epidermal Growth Factor. Int J Dentistry Oral Sci. 2021;8(7):3491-3496. doi: http://dx.doi.org/10.19070/2377-8075-21000713

Copyright: Mohamed Shamel ${ }^{\circ} 2021$. This is an open-access article distributed under the terms of the Creative Commons Attribution License, which permits unrestricted use, distribution and reproduction in any medium, provided the original author and source are credited. 
Numerous studies have been reported in the literature with regards to the benefits of BTX in the treatment of hypersalivation due to different aetiological factors [11-13]. Literature evaluating the histological and ultrastructural effects of BTX on the salivary glands is scarce $[11,14,15]$, and to date, no clinical trials associated with epidermal growth factor (EGF) injection in BTX treated salivary glands have been reported. Therefore, the aim of the present investigation is to study the possible effects of the most commonly used commercial brand of Botulinum toxin - Botox ${ }^{\circledR}$ (Allergan Inc. Irvine, CA, USA) either separately or coupled with Epidermal Growth Factor (Biovision Inc. Milpitas, CA, USA) on the submandibular salivary glands of adult female Albino rats through immunohistochemical localization of the cytokeratin in the parenchyma of the gland.

\section{Materials and Methods}

This project was reviewed and granted ethical approval by the Suez Canal University Research Ethics Committee (SUEZ-REC 35/2014).

Sixty healthy adult female Albino rats, three months old and 200$220 \mathrm{gm}$ body weight were used in this study. The rats were obtained from Kasr El Aini animal experimental unit, Faculty of Medicine, Cairo University. The rats were housed in separate cages, five rats per cage and kept in an environment with controlled temperature $\left(25^{\circ} \mathrm{C}\right)$, humidity $(45 \%-75 \%)$, and photoperiod $(12: 12$ hour lightdark cycle). The animals were fed natural diet and supplied drinking water Ad Libitum throughout the whole experimental period. The rats were acclimatized for one week before the initiation of the experiment.

The animals were randomly divided into three groups as follows: Control group: consisted of 20 rats, subjected to subcutaneous injection of $0.1 \mathrm{ml}$ saline in the region of the right and left submandibular salivary glands and served as controls.

Botox $^{\circledR}$ (BTX) group: consisted of 20 rats that were subjected to single dose of subcutaneous injection of 2.5 unit botulinum toxin type A - Botox ${ }^{\circledR}$ (Allergan Inc. Irvine, CA, USA), reconstituted in $0.1 \mathrm{ml}$ of physiologic saline in the region of the right and left submandibular salivary glands [8].

EGF group (Botox ${ }^{\circledR}+$ Epidermal growth factor): consisted of 20 rats, that were injected once subcutaneously with 2.5 unit botulinum toxin in $0.1 \mathrm{ml}$ saline (Allergan Inc. Irvine, CA, USA) as in BTX group and on the next day they were subjected to daily intra peritoneal injection of Epidermal Growth Factor (Biovision Inc.
Milpitas, CA, USA) in a dose of $10 \mu \mathrm{g} / \mathrm{Kg}$ body weight for sixty days [16].

At the end of the experiment, all animals were sacrificed by euthanasia and thseir submandibular salivary glands were dissected immediately after euthanasia.

Submandibular salivary glands were processed for histological examination and stained with Immuno-peroxidase staining for immunohistochemical localization of cytokeratin in the glandular tissue using staining reaction incubated by Anticytokeratin - CK number 5,6 and 18 Antibody (Thermo Fisher Scientific, Scoresby, VIC, Australia).

For cytokeratin immunohistochemical localization, negative controls were prepared by substituting the primary antibody by a nonspecific serum of the same dilution as its respective antibody and the procedures were continued as usual. Six sections from each submandibular salivary glands stained with anticytokeratin antibody were selected, examined with ZEISS Primo Star light microscopy and photographed by Tucsen IS 1000 10.0MP Camera in the Oral Biology Laboratory, Faculty of Dentistry, British University in Egypt.

The staining reaction of the different immunohistochemical parameters of the different groups was scored as follows:

$(-)$ negative staining reactivity.

$(+)$ weak positive staining reactivity.

$(++)$ moderate positive staining reactivity.

$(+++)$ strong positive staining reactivity.

The intensity of the immunohistochemical staining results from different groups were histomorphometrically analyzed using Image J computer system (1.46 a, NIH, USA). For each selected section, six microscopic fields were selected and captured at a magnification 200X using a digital video camera mounted on a light microscope (CX21, Olympus, Japan). Images were then transferred to the computer system for analysis.

Images were manually corrected for brightness and contrast. Color thresholding was then performed automatically after which pictures were converted to RGB stack type. Masking of the brown cytokeratin, immuno-stain was performed by red color where any brown stain of any intensity was considered positive whereas the background grey stain was considered negative (Fig. 1). Area fraction was then calculated automatically representing the area percentage of immune positive cells to the total area of the microscopic field.

Figure 1. Showing an example of the cytokeratin expression in the control group (a) and in the EGF group (b). Cytokeratin expression was masked in red color using the Image $\mathrm{J}$ computer software.

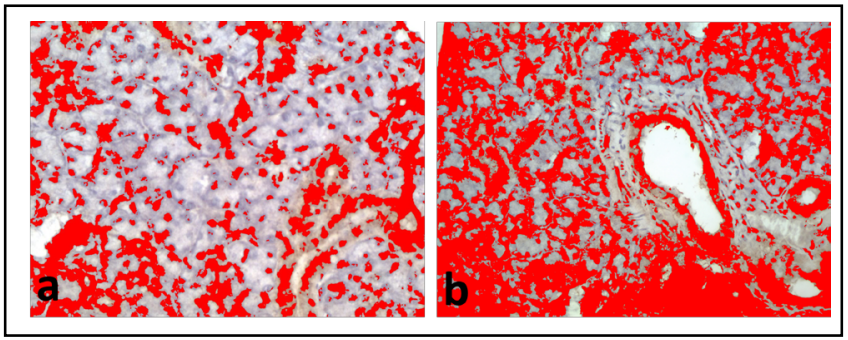




\section{Statistics}

All data obtained from histomorphometric analysis was statistically described in terms of range, mean, \pm standard deviation $( \pm \mathrm{SD})$, and median. Comparison between groups was done using Kruskal Wallis analysis of variance (ANOVA) test with ConoverInman test for independent samples as post hoc multiple 2-group comparisons. A p value of $<0.05$ was considered statistically significant. All statistical analysis was done using the Statistical Package for the Social Sciences version 21 (SPSS Inc., Chicago, IL).

\section{Results}

\section{Negative Control}

Sections taken from the submandibular salivary glands of rats from the control group and incubated with non-specific serum and colour developed by $\mathrm{DAB}$ revealed negative staining reaction of all elements forming the glands.

\section{Control Group}

Serous secretory cells showed a moderate to strong positive staining reaction of their cytoplasm while mucous secretory cells represented negative staining pattern. Strong positive reaction was detected in most of the tissue sections around the secretory acini (Fig. 2a).

All the duct system including the intercalated duct, granular convoluted tubules, the striated ducts as well as the excretory ducts revealed strong positive staining reaction. The pattern of staining represented as diffuse cytoplasmic staining in the striated and excretory ducts while the granular convoluted tubules showed staining at the granular parts. Moderate to strong positive staining reaction was found in the connective tissue surrounding the excretory ducts as well as walls of the blood vessels (Figs. 2a, 2b).

\section{Botox ${ }^{\circledR}$ group}

Serous secretory acini revealed negative to weakly positive staining to anticytokeratin antibody. Intercalated, striated and excretory ducts as well as granular convoluted tubules showed weakly positive staining reaction while connective tissue cells and walls of blood vessels walls showed weakly positive staining reaction (Figs. 2c, 2d).

\section{EGF group (Botox ${ }^{\circledR}+$ Epidermal Growth Factor):}

Serous secretory cells showed moderate to strong positive reaction of their cytoplasm and strong positive reaction were observed around the secretory acini in most of the tissue sections (Figs. 2e, 2f).

Ductal cells of intercalated, striated and excretory ducts showed strong positive reaction represented as diffuse cytoplasmic staining while granular convoluted tubules showed strong positive reaction at the granular parts. Moderate to strongly positive staining reaction was found in the connective tissue surrounding the excretory ducts as well as the walls of the blood vessels (Fig $2 \mathrm{f}$ ). Table 1 summarizes the staining intensity of cytokeratin in differ-

Figure 2. A photomicrograph of the rat submandibular salivary gland. (a): Control group showing moderate to strong positive reaction in acini (black arrows) and strong positive reaction in ductal cells (red arrows) to cytokeratin 5,6 \&18 (anticytokeratin original mag. $x$ 100). (b): Control group showing strong positive reaction in excretory ductal cells (red arrows) to cytokeratin 5,6 \&18 (anticytokeratin original mag. x 200). (c): Botox (BTX) group showing weak reaction in acini and ductal cells (black arrows) to cytokeratin 5,6 \&18 (anticytokeratin original mag. x 100). (d): Botox (BTX) group showing weak positive reaction in acini (black arrows) and moderate positive reaction (red arrows) in excretory ductal cells to cytokeratin 5,6 \&18 (anticytokeratin original mag. $x$ 100). (e): Epidermal Growth Factor (EGF) group showing moderate to strong positive reaction (black arrows) in acini to cytokeratin 5,6 \&18 (anticytokeratin original mag. x 200). (f): Epidermal Growth Factor (EGF) group showing moderate to strong positive reaction in acini (black arrows) and ductal cells (red arrows) to cytokeratin 5,6 \&18 (anticytokeratin original mag. $x$ 200).

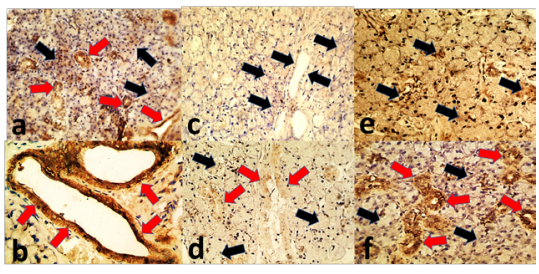

Table 1. Illustrates the staining intensity scores of the submandibular salivary glands to Cytokeratin.

\begin{tabular}{|c|c|c|c|}
\hline Group & Control & Botox & EGF \\
\hline Serous cells & $++/+++$ & $-/+$ & $++/+++$ \\
\hline Mucous cells & - & - & - \\
\hline Myoepithelial cells & ++ & $-/+$ & ++ \\
\hline Intercalated ducts & +++ & + & +++ \\
\hline Striated cells & +++ & + & +++ \\
\hline Granular convoluted tubules & +++ & + & +++ \\
\hline Excretory ducts & +++ & + & +++ \\
\hline Connective tissue cells & $++/+++$ & + & $++/+++$ \\
\hline Wall of blood vessels & $++/+++$ & + & $++/+++$ \\
\hline
\end{tabular}

- Negative staining reactivity. + Weak positive staining reactivity. ++ Moderate positive staining reactivity. +++ Strong positive staining reactivity. 
ent components of the submandibular salivary glands.

\section{Statistical Results}

Histomorphometric analysis: Histomorphometric analysis of the three groups of the submandibular salivary gland revealed that the highest mean area percent occupied by cytokeratin immunostaining was recorded in the control group, whereas the lowest

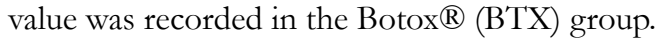

Statistical analysis of variance (ANOVA test), revealed that the difference in the mean area percent of expression of cytokeratin immunostaining was extremely statistically significant $(p<0.0001)$. The mean values of the cytokeratin mean area percentage in all groups of submandibular salivary gland were summarized in table 2.

\section{Comparison between different groups}

A pairwise comparison was held between cytokeratin mean area expression percentage in control group and the other experimental groups using an unpaired (independent) Student's t-test (Table $3)$.

There was a statistically significant decrease in the cytokeratin expression area percentage in the BTX group than the control group $(\mathrm{p}<0.0001)$. Furthermore, there was a statistically significant increase in the cytokertain expression area percentage in EGF group when compared to the BTX group $(\mathrm{p}<0.0001)$. Finally, there was a slight decrease in the cytokeratin expression area percentage in the EGF group when compared to the control group which was not statistically significant.

\section{Discussion}

Botulinum toxin (BTX), that is known to inhibit the release of acetylcholine in different types of nerve endings, was used in this study separately or in conjunction with epidermal growth fac- tor (EGF) to detect their opposing effects on the submandibular salivary gland of female Albino rats. Botox ${ }^{\circledR}$ was chosen in the present study as it is currently the most cosmetic injectable product widely used in the world [16]. Furthermore, the clinical applications of BTX extend beyond facial cosmetic therapy. BTX injections are a safer treatment modality for other non-cosmetic procedures when compared to pharmacotherapy or surgical intervention in terms of complications and mortality. These non-cosmetic applications include salivary secretory disorders, excessive sweating, facial pain, and head and neck movement disorders [17]. In the present study, EGF was used to investigate its repair and healing capacity in the submandibular salivary gland after BTX injection as EGF has emerged as a powerful regulator of stem cells and tissue regeneration $[18,19]$.

Keratins have an influence on the mitotic activity and the architecture (e.g. cell polarity and cell shape) of epithelial cells. They are described to provide a scaffold (through self-bundling and by forming thicker strands) for epithelial cells and tissues to resist mechanical stress, maintain structural integrity, mechanical resilience and cell polarity, as well as protect against changes in hydrostatic pressure [20,21]. Furthermore, keratins and keratin filaments are associated with other cellular functions such as cell signalling, cell transport, cell compartmentalization and cell differentiation [22]. Keratin filaments also influence cell metabolic processes by regulating protein synthesis and cell growth [23, 24]. Therefore, Cytokeratin was chosen in the present study as an immunohistochemical marker to evaluate the extent of damage caused by botulinum toxin as well as evaluate the amount of repair after administration of EGF.

In the present investigation, the submandibular salivary glands of the Botox ${ }^{\circledR}$ (BTX) group, represented a weak positive reaction to cytokeratins \# 5,6 and 18, which was in contrast to a strong reaction in the control group. Moreover, myoepithelial cells were stained positively in the control group and showed weak positive staining reactivity in the BTX group. The decrease in the cytokeratin expression in BTX group could be explained to be a result

Table 2. Illustrates the mean values and standard deviation (SD) of the area percentage of expression of Cytokeratin immunostaining in the submandibular salivary gland of the different groups.

\begin{tabular}{|c|c|c|c|}
\hline Group & Control group & BTX group & EGF group \\
\hline No. of cases & 20 & 20 & 20 \\
\hline Max & 63.03 & 26.21 & 61.75 \\
\hline Min & 47.84 & 18.96 & 41.63 \\
\hline Mean & 56.51 & 21.01 & 47.67 \\
\hline SD & 4.67 & 1.98 & 3.84 \\
\hline Median & 57.75 & 20.66 & 47.4 \\
\hline
\end{tabular}

Table 3. Illustrates the results of the descriptive statistical pairwise comparison between cytokeratin area percentage in the submandibular salivary gland of the control group and other groups.

\begin{tabular}{|c|c|c|c|}
\hline Comparison & Mean difference $\mathbf{L}$ & T value & P value \\
\hline Control vs. Botox & 35.537 & 27.215 & $<0.0001 *$ \\
\hline Control vs. EGF & 8.844 & 9.232 & 0.922 \\
\hline Botox vs. EGF & 26.665 & 13.455 & $<0.0001 *$ \\
\hline
\end{tabular}

* Statistically significant 
of the atrophic and degenerative changes caused by the BTXA to different parenchymal elements within the submandibular salivary glands which causes deformation in the acinar cells and defects within the cellular junctions which ultimately results in reduction in the secretory function of the acini. This is in agreement with several studies which reported that changes from the normal architecture of the gland could potentially affect the glands adversely [24-26] and is associated with a decrease or negative reactivity to cytokeratin [27-29]. Furthermore, it has been reported that Botox ${ }^{\circledR}$ has a number of adverse effects on submandibular salivary glands including the reduction of Myosin expression and changes to the ultrastructure picture $[30,31]$.

The repair potential and healing capacity of Epidermal Growth Factor (EGF) has been reported in a number studies including reversing the damage caused by a number of factors including Diabetes Mellitus [32-35]. The findings from the current study are in alignment with previous studies where EGF restored the normal cytokeratin levels in acinar and ductal cells after a single Botox ${ }^{\circledR}$ injection.

Cytokeratin \# 5,6 and 18 expression in the EGF group was similar to the control group. Serous acini and ductal cells showed strong to moderate reaction reactivity. The stronger reaction revealed by the duct cells is explained by the sequence of cytodifferentiation of the ductal cells before the terminal branches, as the acinar cells are the last to develop, which results in less cytokeratin formation. In addition to the above, myoepithelial cells were evident in the surroundings of the acini and intercalated ducts and were stained positively confirming its epithelial character. No statistically significant difference was found in the mean area percentage of cytokeratin expression between control and EGF groups. These results are in alignment with a number studies that identified cytokeratin 5, 6 and 18 expression as a common finding in cytoplasm of serous acini and ducts of normal salivary glands $[27,28,36,37]$.

\section{Conclusion}

EGF plays an important role in tissue regeneration of the submandibular salivary glands following damage sustained as a result of Botox ${ }^{\circledR}$ (BTX) injection. Daily intraperitoneal injection of epidermal growth factor in a dose of $10 \mu \mathrm{g} / \mathrm{Kg}$ body weight for two months can reverse the damage caused by a single Botox ${ }^{\circledR}$ (BTX) injection and restore the normal features of the submandibular salivary gland. This was confirmed by immunohistochemical localization of cytokeratin expression.

\section{Recommendations and future research}

Further research is being conducted by our team to investigate the effect of EGF on the submandibular salivary glands in albino rats treated with Botox ${ }^{\circledR}$ through localization of E-cadherin. The finding obtained from all immunohistochemical markers will be confirmed using histological examination.

\section{Acknowledgements}

This project was reviewed and granted ethical approval by the Suez Canal University Research Ethics Committee (SUEZ-REC 35/2014).

\section{References}

[1]. Popoff MR, Bouvet P. Genetic characteristics of toxigenic Clostridia and toxin gene evolution. Toxicon. 2013 Dec 1;75:63-89.Pubmed PMID: 23707611.

[2]. Barash JR, Arnon SS. A novel strain of Clostridium botulinum that produces type B and type H botulinum toxins. J Infect Dis. 2014 Jan 15;209(2):18391.Pubmed PMID: 24106296.

[3]. Dover N, Barash JR, Arnon SS. Novel Clostridium botulinum toxin gene arrangement with subtype A5 and partial subtype B3 botulinum neurotoxin genes. J Clin Microbiol. 2009 Jul;47(7):2349-50.Pubmed PMID: 19420169.

[4]. Dover N, Barash JR, Hill KK, Xie G, Arnon SS. Molecular characterization of a novel botulinum neurotoxin type $\mathrm{H}$ gene. J Infect Dis. 2014 Jan 15;209(2):192-202.Pubmed PMID: 24106295.

[5]. Kalb SR, Santana WI, Geren IN, Garcia-Rodriguez C, Lou J, Smith TJ, et al. Extraction and inhibition of enzymatic activity of botulinum neurotoxins / B1, /B2, /B3, /B4, and /B5 by a panel of monoclonal anti-BoNT/B antibodies. BMC Biochem. 2011 Nov 15;12:58.Pubmed PMID: 22085466.

[6]. Jankovic J, Comella C, Hanschmann A, Grafe S. Efficacy and safety of incobotulinumtoxinA (NT 201, Xeomin) in the treatment of blepharospasma randomized trial. Mov Disord. 2011 Jul;26(8):1521-8.Pubmed PMID: 21520284.

[7]. Adler CH. Perioperative use of botulinum toxins. Toxicon. 2009 Oct;54(5):654-7.Pubmed PMID: 19084551.

[8]. Ellies M, Gottstein U, Rohrbach-Volland S, Arglebe C, Laskawi R. Reduction of salivary flow with botulinum toxin: extended report on 33 patients with drooling, salivary fistulas, and sialadenitis. Laryngoscope. 2004 Oct;114(10):1856-60.Pubmed PMID: 15454785.

[9]. Sim WS. Application of botulinum toxin in pain management. Korean J Pain. 2011 Mar;24(1):1-6.Pubmed PMID: 21390172.

[10]. Gerlinger I, Szalai G, Hollódy K, Németh A. Ultrasound-guided, intraglandular injection of botulinum toxin $\mathrm{A}$ in children suffering from excessive salivation. J Laryngol Otol. 2007 Oct;121(10):947-51. Pubmed PMID: 17391573.

[11]. Shan XF, Xu H, Cai ZG, Wu LL, Yu GY. Botulinum toxin A inhibits salivary secretion of rabbit submandibular gland. Int J Oral Sci. 2013 Dec;5(4):21723.Pubmed PMID: 24158141.

[12]. Jongerius PH, Rotteveel JJ, van Limbeek J, Gabreëls FJ, van Hulst K, van den Hoogen FJ. Botulinum toxin effect on salivary flow rate in children with cerebral palsy. Neurology. 2004 Oct 26;63(8):1371-5.Pubmed PMID: 15505151.

[13]. Sriskandan N, Moody A, Howlett DC. Ultrasound-guided submandibular gland injection of botulinum toxin for hypersalivation in cerebral palsy. $\mathrm{Br}$ J Oral Maxillofac Surg. 2010 Jan;48(1):58-60.Pubmed PMID: 19371986.

[14]. Younis RE, Abou Elkhier MT, Mourad MI, Elnahas W. Ultrastructural changes in the parotid gland of rats after intraglandular injection of botulinum toxin A. Ann. Maxillofac. Surg. 2013;1(4):38.

[15]. Teymoortash A, Sommer F, Mandic R, Schulz S, Bette M, Aumüller G, et al. Intraglandular application of botulinum toxin leads to structural and functional changes in rat acinar cells. Br J Pharmacol. 2007 Sep;152(1):161-7. Pubmed PMID: 17618309.

[16]. Kane CD, Nuss JE, Bavari S. Novel therapeutic uses and formulations of botulinum neurotoxins: a patent review $(2012$ - 2014). Expert Opin Ther Pat. 2015 Jun;25(6):675-90.Pubmed PMID: 25842964.

[17]. Alshadwi A, Nadershah M, Osborn T. Therapeutic applications of botulinum neurotoxins in head and neck disorders. Saudi Dent J. 2015 Jan;27(1):3-11. Pubmed PMID: 25544809.

[18]. Jutten B, Rouschop K. EGFR signaling and autophagy dependence for growth, survival, and therapy resistance. Cell Cycle. 2013;13(1):42-51. PMID: 24335351.

[19]. Strand M, Micchelli CA. Regional control of Drosophila gut stem cell proliferation: EGF establishes GSSC proliferative set point \& controls emergence from quiescence. PLoS One. 2013 Nov 13;8(11):806-808.Pubmed PMID: 24236188.

[20]. Coulombe PA, Omary MB. 'Hard' and 'soft' principles defining the structure, function and regulation of keratin intermediate filaments. Curr Opin Cell Biol. 2002 Feb;14(1):110-22.Pubmed PMID: 11792552.

[21]. Kim S, Wong P, Coulombe PA. A keratin cytoskeletal protein regulates protein synthesis and epithelial cell growth. Nature. 2006 May 18;441(7091):362-5.Pubmed PMID: 16710422.

[22]. Vaidya MM, Kanojia D. Keratins: markers of cell differentiation or regulators of cell differentiation?. J Biosci. 2007 Jun;32(4):629-34.Pubmed PMID: 17762135 .

[23]. Kose O, Stewart J, Waseem A, Lalli A, Fortune F. Expression of cytokeratins, 
adhesion and activation molecules in oral ulcers of Behçet's disease. Clin Exp Dermatol. 2008 Jan;33(1):62-9.Pubmed PMID: 17983454.

[24]. Shamel M, Riad D, Al Ankily M. Histological and Ultrastructural Study Of Silver Nanoparticles Toxicity and The Possible Protective Effect Of Vitamin C On Submandibular Salivary Glands Of Albino Rats. Int J Dentistry Oral Sci. 2021 Apr 2;8(04):2166-71.

[25]. Ashraf B, Ghazy D, Shamel M. Effects of aflatoxin B1 on the submandibular salivary gland of albino rats and possible therapeutic potential of Rosmarinus officinalis: a light and electron microscopic study. F1000Res. $2020 \mathrm{Jul}$ 21;9:752.Pubmed PMID: 32789012.

[26]. Mansy M, Soliman M, Mubarak R, Shamel M. The role of exogenous epidermal growth factor on Ki-67 proliferation marker expression in the submandibular salivary gland of albino rats receiving doxorubicin. F1000Res. 2020 Dec 3;9:1393.Pubmed PMID: 33456767.

[27]. Berkovitz BK, Barrett AW. Cytokeratin intermediate filaments in oral and odontogenic epithelia. Bull Group Int Rech Sci Stomatol Odontol. 1998 Jan-Mar;40(1):4-23.Pubmed PMID: 9567450

[28]. Azevedo RS, de Almeida OP, Kowalski LP, Pires FR. Comparative cytokeratin expression in the different cell types of salivary gland mucoepidermoid carcinoma. Head Neck Pathol. 2008 Dec;2(4):257-64.Pubmed PMID: 20614291

[29]. Dăguci L, Stepan A, Mercuţ V, Dăguci C, Bătăiosu M, Florescu A. Immunohistochemical expression of CK7, CK5/6, CK19, and p63 in Warthin tumor. Rom J Morphol Embryol. 2012;53(3):603-7.Pubmed PMID: 22990554.

[30]. Shamel M, Al Ankily MM, Bakr MM. Epidermal growth factor restores normal levels of myosin expression in submandibular salivary glands of rats treated with botulinum toxin. J Adv Med Dent Sci Res. 2017;5(1):1-6.

[31]. Shamel M, Al-ankily MM, Bakr MM, ElKholy M. EPIDERMAL GROWTH FACTOR IMPROVES THE ULTRASTRUCTURAL PICTURE OF SUBMANDIBULAR SALIVARY GLANDS OF ALBINO RATS TREATED WITH A SINGLE BOTULINUM TOXIN INJECTION-A QUALITATIVE STUDY. Eur J of Pharma and Med Res. 2020;7(11):88-94.

[32]. Al-Ankily MM, Shamel M, Bakr MM. Epidermal growth factor and diabetes mellitus; friends or faux?. Int. j. med. dent. Sci. 2016 Jul 14;5(2):1290-6.

[33]. Shamel M, Ankily MM, Bakr MM. Epidermal growth factor (EGF) and botulinum toxin (BTX); can paralysis be a bless?. J Res Med Dent Sci. 2016;4(1):1-9

[34]. Al-Ankily MM, Shamel M, Bakr M. Epidermal growth factor restores cytokeratin expression in rats with diabetes. J Res Med Dent Sci. 2018 Feb 1;6(1):196-203.

[35]. Al Ankily M, Shamel M, Bakr MM. Epidermal Growth Factor Improves the Ultrastructure of Submandibular Salivary Glands of Streptozotocin Induced Diabetic Rats-A Qualitative Study. Int J Med Dent Sci. 2020 Feb 5;9(1):1803-10.

[36]. Kummar S, Fogarasi M, Canova A, Mota A, Ciesielski T. Cytokeratin 7 and 20 staining for the diagnosis of lung and colorectal adenocarcinoma. $\mathrm{Br} \mathrm{J}$ Cancer. 2002 Jun 17;86(12):1884-7.Pubmed PMID: 12085180

[37]. Kusama K, Jiang Y, Ohno J, Shikata H, Ishikawa F, Taguchi K, et al. Immunohistochemical detection of cytokeratin 18 and its neo-epitope in human salivary glands and pleomorphic adenomas. Anticancer Res. 2000 JulAug;20(4):2485-7.Pubmed PMID: 10953315. 